\title{
Non-equilibrium solidification of undercooled droplets during atomization process
}

\author{
PRASHANT SHUKLA, R K MANDAL and S N OJHA* \\ Centre of Advanced Study, Department of Metallurgical Engineering, Banaras Hindu University, Varanasi 221 005, India
}

MS received 1 March 2000; revised 13 July 2000

\begin{abstract}
Thermal history of droplets associated with gas atomization of melt has been investigated. A mathematical model, based on classical theory of heterogeneous nucleation and volume separation of nucleants among droplets size distribution, is described to predict undercooling of droplets. Newtonian heat flow condition coupled with velocity dependent heat transfer coefficient is used to obtain cooling rate before and after nucleation of droplets. The results indicate that temperature profile of droplets in the spray during recalescence, segregated and eutectic solidification regimes is dependent on their size and related undercooling. The interface temperature during solidification of undercooled droplets rapidly approaches the liquidus temperature of the alloy with a subsequent decrease in solid-liquid interface velocity. A comparison in cooling rates of atomized powder particles estimated from secondary dendrite arm spacing measurements are observed to be closer to those predicted from the model during segregated solidification regime of large size droplets.
\end{abstract}

Keywords. Atomization; droplets; undercooling; solidification; recalescence; cooling rates.

\section{Introduction}

Atomization of melt by high energy gas jets is a well established technique for production of rapidly solidified powders. The inert gas serves two basic functions in this process. Initially, it transfers sufficient kinetic energy to shear and disrupt the melt stream into micron size droplets which are subsequently accelerated in the gas stream. Secondly the gas facilitates rapid cooling of droplets by mode of heat flow by forced convection during their flight. Solidification of droplets during flight in an atomization chamber is used to produce powders which are then consolidated following powder metallurgy methods (Sanctis 1991). Alternatively, the spray of droplets is directed towards a stationary or movable substrate to deposit and consolidate into a near net shape preform in a spray forming process (Ojha et al 1991; Lavernia and Wu 1996). In both the approaches, rapid solidification (RS) effects are produced in sufficiently small size droplets due to their increased surface-to-volume ratio and effective heat exchange at the droplet-gas interface. In addition heterogeneous nucleation catalysts are isolated by volume separation into small number of droplets. Most of droplets devoid of nucleants are subjected to large undercooling prior to nucleation of the solid phase. The large undercooling has been considered to further aid evolution of rapid solidification microstructures (Ojha et al 1985; Pandey et al 1994).

\footnotetext{
*Author for correspondence
}

In the past gas atomization technology has lagged behind the need for generation of small size droplets so as to induce RS effects in resulting powders or spraydeposit. Atomization efficiency is reduced when the exit of the gas jet is remote from the melt stream. The melt atomization processes working on this principle on a commercial scale produces powder particles often greater than $200 \mu \mathrm{m}$ with cooling rate of droplets varying within $10^{2}$ to $10^{4} \mathrm{~K} \mathrm{~s}^{-1}$ (Klar and Fesko 1984). The requirements to achieve maximum yield of fine droplets, usually of size less than $100 \mu \mathrm{m}$ in the spray, has necessitated efficient design of spray nozzles to facilitate better gas-metal interaction. One such design which has created considerable interest in recent years involves close couple configuration of the gas metal stream to promote efficient atomization of the melt (Unal 1987; Singh and Ojha 1992).

The microstructure evolution during solidification of droplets depends in a complex way on the nature of heterogeneous nucleants present in the melt and related undercooling of droplets. The influence of both these effects in gas atomization processes are difficult to assess due to difficulty in measurement of nucleation temperature of droplets in flight. As a result thermal states of droplets in spray atomization are predicted using numerical models (Lavernia et al 1988; Mathur et al 1989; Grant et al 1993). In the present investigation an analysis of heterogeneous nucleation in gas atomized droplets has been attempted based on available theoretical and experimental observations. Subsequently nature of 
non-equilibrium solidification of undercooled droplets in spray atomization is discussed.

\section{Modelling of droplet solidification}

In this model size dependent nucleation temperature of droplet is predicted based on nucleant distribution and classical theory of nucleation. Subsequently, solidification behaviour of droplets is analysed during their five distinct stages of cooling. These include (i) cooling of droplets in the liquid state till nucleation temperature is reached, (ii) recalescence of the undercooled melt followed by (iii) segregated and (iv) eutectic solidification and finally (v) cooling in the solid state.

\section{$2.1 \quad$ Nucleation undercooling}

Undercooling of a melt is influenced by several factors such as nucleation sites, potency of nucleants and their volume distribution. In gas atomization process wide size range of droplets are generated. The success of achieving large undercooling of droplets depends on degree of volume separation of nucleants existing in the melt. Although their presence is difficult to detect, theoretical approaches have been used to study the distribution of such nucleants (Drehman and Turnbull 1981; Adkins and Tsakiropoulous 1991). In this analysis, assumption is made that finite number of nucleants are randomly distributed in the bulk melt with their identical size and catalytic potency. The degree of dispersion of nucleants within droplets is represented by Poisson distribution function. The fraction of droplets free from nucleant $\left(F_{\mathrm{n}}\right)$ is given by

$$
F_{\mathrm{n}}=\exp \left(-1 / 6 \pi N_{\mathrm{v}} d^{3}\right)
$$

where $N_{\mathrm{v}}$ is nucleant density in the bulk melt and $d$ the droplet diameter. The magnitude of nucleant density has been estimated to vary from $10^{12}$ to $10^{13} \mathrm{~m}^{-3}$ based on experimental observations in atomization of $\mathrm{Al}-5.5 \mathrm{wt} \%$ $\mathrm{Cu}$ (Boettinger and Perepezko 1985) and fraction of glassy powders in $\mathrm{Pd}-\mathrm{Si}$ alloys (Drehman and Turnbull 1981). Using the above values of nucleant density in the melt, the fraction of droplets free from heterogeneous nucleants as a function of droplet diameters in Al-4.5 Cu alloy is shown in figure 1 . It is worthwhile to note that as the droplet diameter decreases to $20 \mu \mathrm{m}$ the fraction of droplets free from nucleants approaches unity. On the other hand as the droplet diameters increases the fraction free from nucleants decreases and becomes substantially low for droplets $>180 \mu \mathrm{m}$ size for two different nucleant densities in the melt. Consequently all droplets $<10 \mu \mathrm{m}$ are considered to undergo homogeneous nucleation condition as these are devoid of heterogeneous nucleants. Large size droplets $>180 \mu \mathrm{m}$ is subjected to heterogeneous nucleation condition. The nucleation temperature of intermediate size droplets varies with their size in the spray.
The steady-state nucleation rate $I(T)$, which is the number of nuclei per unit volume per unit time is given by classical nucleation theory (Hirth 1978)

$$
I(T)=K_{v} \exp \left[\frac{-16 \pi T_{\mathrm{L}}^{2} \sigma_{\mathrm{sl}}^{3} f(\theta)}{3 k_{\mathrm{B}} T_{\mathrm{d}} \rho_{\mathrm{d}}^{2} \Delta H_{\mathrm{f}}^{2}\left(T_{\mathrm{L}}-T_{\mathrm{d}}\right)^{2}}\right],
$$

where $k_{\mathrm{B}}$ is Boltzmann constant, $K_{v}$ is a kinetic factor whose magnitude is estimated to be of the order of $10^{40} \mathrm{~m}^{-3} \mathrm{~s}^{-1}$ by Cantor and Doherty (1979). The difficulty in determining an exact value of the nucleating potency of a nucleant is described by a function $f(\theta)$ which is given as:

$$
f(\theta)=\frac{(2+\cos \theta)(1-\cos \theta)^{2}}{4},
$$

where $\theta$ is contact angle between a nucleant and the crystal nucleus. A higher value of $\theta$ implies poor wetting between the liquid and the nucleant and hence higher undercooling of the droplet. Considering droplet size limits of 10 and $180 \mu \mathrm{m}$ for homogeneous and heterogeneous nucleation condition respectively, the expression for size dependent nucleation temperature of droplets can be obtained as

$$
f(\theta)=a+b d^{-1}
$$

where the constants $a$ and $b$ are -0.06 and $10.6 \mu \mathrm{m}$, respectively. Assuming that the formation of a single nucleus represents the onset of nucleation in a droplet with a volume $V_{\mathrm{d}}$, the critical condition for the onset of nucleation is described as

$$
V_{\mathrm{d}} \int_{T_{\mathrm{N}}}^{T_{\mathrm{L}}} \frac{I(T)}{\dot{T}} \mathrm{~d} T=1
$$

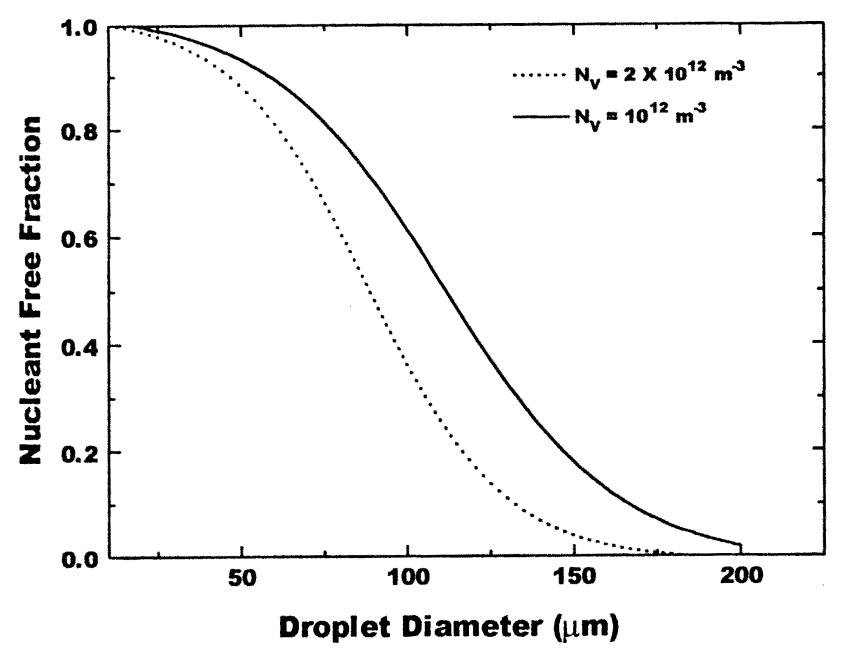

Figure 1. Variation in nucleant free fraction of droplets as a function of droplet diameters. 
The nucleation rate $I(T)$ for a melt undercooling $(\Delta T)$ depends exponentially on $1 / T(\Delta T)^{2}$ and is nearly zero except for a very small temperature range near $T_{\mathrm{N}}$ (Kurz and Fischer 1989). The integrand is approximated as a Dirac delta function and the integral can be replaced by its value at nucleation temperature $\left(T_{\mathrm{N}}\right)$. The difficulties that are associated with integration of expression (4) is overcome by numerical approaches. Accordingly, Hirth (1978) expanded the nucleation rate in the above equation around the nucleation temperature using the Taylor series. Consequently (4) reduces to

$$
\frac{0 \cdot 01 I\left(T_{\mathrm{N}}\right) V_{\mathrm{d}}\left(T_{\mathrm{L}}-T_{\mathrm{N}}\right)}{\dot{T}} \cong 1
$$

Equations (3) and (5) are used to calculate the nucleation temperature of droplets with different catalytic potency represented by contact angle, $\theta$. It is worthwhile to mention that non-steady state nucleation occurs during the initial transient stages wherein nucleation rate increases with time. In case of rapid cooling of droplets in atomization processes, non-steady state nucleation has important influence on the onset temperature of nucleation. Since the highest possible nucleation rate corresponds to steady state nucleation, (4) may lead to overestimation of nucleation temperature of droplets.

\subsection{Solidification of undercooled droplets}

The generalized heat balance equation for a droplet solidification is given as

$$
C_{\mathrm{pd}} \frac{\mathrm{d} T_{\mathrm{d}}}{\mathrm{d} t}=\Delta H_{\mathrm{d}} \frac{\mathrm{d} f_{\mathrm{s}}}{\mathrm{d} t}-\frac{6 h}{\rho_{\mathrm{d}} d}\left(T_{\mathrm{d}}-T_{\mathrm{g}}\right),
$$

where $C_{\mathrm{pd}}=C_{\mathrm{L}}-\left(C_{\mathrm{L}}-C_{\mathrm{S}}\right) f_{\mathrm{s}}$ and $\Delta H_{\mathrm{d}}=\Delta H_{\mathrm{f}}-\left(C_{\mathrm{L}}-C_{\mathrm{S}}\right)$ $\left(T_{\mathrm{L}}-T_{\mathrm{S}}\right)$.

The value of convective heat transfer coefficient $(h)$ is obtained by the well-known correlation of Ranz and Marshall (1952) as

$$
h=\frac{k_{\mathrm{g}}}{d}(2 \cdot 0+0 \cdot 6 \sqrt{\operatorname{Re}} \sqrt[3]{\operatorname{Pr}})
$$

where $k_{\mathrm{g}}$ is the gas thermal conductivity, $\operatorname{Pr}$ the gas Prandtl number given by $\left(C_{\mathrm{pg}} \mu_{\mathrm{g}} / k_{\mathrm{g}}\right)$ and $R e$ the Reynolds number, defined by $\left(\rho_{\mathrm{g}} \mathrm{d} / \mu_{\mathrm{g}}\right)\left|v_{\mathrm{d}}-v_{\mathrm{g}}\right|$. The heat transfer coefficient at the droplet-gas interface is thus calculated from their relative velocities with gas during flight as described earlier (Singh et al 1992). The decay characteristics of the gas velocity down the exit of the nozzle has been taken from the measured values to incorporate in the model for calculation of the heat transfer coefficient. In gas atomization heat transfer from the droplet surface occurs predominantly by forced convection and the effect of cooling by radiation is neglected in heat balance (6). In addition, for small size droplets achieved in gas atomiza- tion processes heat conduction within the droplet is ignored. Consequently thermal state of droplets is described by Newtonian heat flow condition. During cooling of droplets in the initial stages prior to nucleation and final cooling in solid state, the second term of (6) is ignored and the specific heat data of the respective liquid and solid phases of the alloy are used to describe their thermal state. On the onset of eutectic solidification the temperature of the droplet does not change with time till the solidification is complete.

The phase changes accompanied by solidification are important during the recalescence and post recalescence segregated solidification stages. Subsequent to nucleation of the solid phase in undercooled melt, there is a rapid rise in temperature of the melt. Initial solidification of undercooled droplet during this stage occurs by diffusionless process with a planar solid-liquid interface. The interface velocity for this condition is described as

$$
\frac{\mathrm{d} x}{\mathrm{~d} t}=K_{\mathrm{i}}\left(T_{\mathrm{L}}-T_{\mathrm{d}}\right)
$$

where $K_{\mathrm{i}}$ is interface attachment coefficient taken as $0.02 \mathrm{~ms}^{-1} \mathrm{~K}^{-1}$ (Levi and Mehrabian 1982). It is important to point out that (8) is applicable for small or moderate undercooling of the melt. The growth velocity for highly undercooled melt shows a power law relationship with melt undercooling (Herlach et al 1993). However, due to lack of information regarding value of $K_{\mathrm{i}}$ for highly undercooled melt, (8) has been invariably applied. Considering nucleation event occurring on droplet surface and the curvature of the nucleus being preserved during growth process as shown schematically in figure 2, the fraction solidified during recalescence stage is represented (Lee and Ahn 1994) by

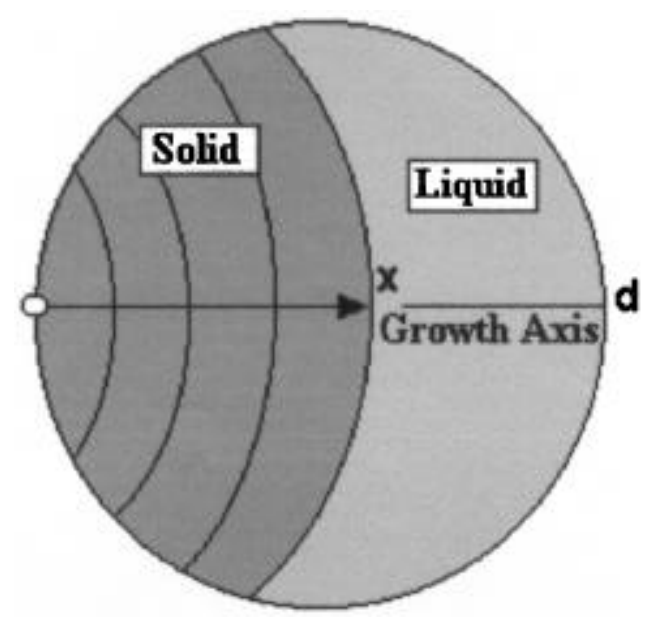

Figure 2. Schematic illustration of interface movement during solidification of undercooled droplet. 


$$
\frac{\mathrm{d} f_{s}}{\mathrm{~d} x}=\frac{1}{d}\left[3\left(\frac{x}{d}\right)-\frac{3}{2}\left(\frac{x}{d}\right)^{2}\right]
$$

Differentiating (8) with respect to ' $t$ ' gives

$$
\frac{\mathrm{d}^{2} x}{\mathrm{~d} t^{2}}=-K_{\mathrm{i}} \frac{\mathrm{d} T_{d}}{\mathrm{~d} t}
$$

Substituting (8) and (9) in (6) gives

$$
\begin{aligned}
\frac{\mathrm{d} T_{d}}{\mathrm{~d} t}= & \frac{\Delta H_{\mathrm{d}}}{C_{\mathrm{pd}}}\left\{\frac{1}{d}\left[3\left(\frac{x}{d}\right)-\frac{3}{2}\left(\frac{x}{d}\right)^{2}\right]\right\} \frac{\mathrm{d} x}{\mathrm{~d} t} \\
& +\frac{6 h}{\rho_{\mathrm{d}} d C_{\mathrm{pd}}}\left[\frac{1}{K_{\mathrm{i}}} \frac{\mathrm{d} x}{\mathrm{~d} t}+\left(T_{\mathrm{g}}-T_{\mathrm{L}}\right)\right] .
\end{aligned}
$$

Substitution of (11) into (10) and rearrangement of terms yield the following expression

$$
\frac{\mathrm{d}^{2} x}{\mathrm{~d} t^{2}}=\left(A_{1} x^{2}+A_{2} x+A_{3}\right) \frac{\mathrm{d} x}{\mathrm{~d} t}+A_{4}
$$

where the constants are defined as

$$
\begin{aligned}
A_{1} & =\frac{3}{2} \frac{K_{\mathrm{i}} \Delta H_{\mathrm{d}}}{C_{\mathrm{pd}} d^{3}}, A_{2}=\frac{-3 K_{\mathrm{i}} \Delta H_{\mathrm{d}}}{C_{\mathrm{pd}} d^{2}}, A_{3}=\frac{-6 h}{C_{\mathrm{pd}} d \rho_{\mathrm{d}}} \\
A_{4} & =\frac{-6 h K_{\mathrm{i}}\left(T_{\mathrm{gas}}-T_{\mathrm{L}}\right)}{\rho_{\mathrm{d}} d C_{\mathrm{pd}}}
\end{aligned}
$$

Integration of (12) gives rise to an expression for obtaining the interface velocity and instantaneous temperature of droplet during recalescence.

$$
\frac{\mathrm{d} x}{\mathrm{~d} t}=\frac{A_{1} x^{3}}{3}+\frac{A_{2} x^{2}}{2}+A_{3} x+A_{4} t+A_{5} .
$$

The constant $A_{5}$ is obtained by boundary condition at the instant of nucleation as $T_{\mathrm{d}}=T_{\mathrm{N}}$ at $x=0$ and $t=0$. This yields $A_{5}=K_{\mathrm{i}}\left(T_{\mathrm{L}}-T_{\mathrm{N}}\right)$.

Table 1. Thermophysical properties of $\mathrm{Al}-4.5 \mathrm{wt} \% \mathrm{Cu}$ alloy (Swaminathan 1992).

\begin{tabular}{lll}
\hline Heat of fusion & $\left(\Delta H_{\mathrm{f}}\right)$ & $3.48 \times 10^{5} \mathrm{~J} \mathrm{~kg}^{-1}$ \\
Density & $\left(\rho_{\mathrm{d}}\right)$ & $2800 \mathrm{~kg} \mathrm{~m}^{-3}$ \\
Specific heat of liquid & $\left(C_{\mathrm{L}}\right)$ & $982 \mathrm{~J} \mathrm{~kg}^{-1} \mathrm{~K}^{-1}$ \\
Specific heat of solid & $\left(C_{\mathrm{s}}\right)$ & $900 \mathrm{~J} \mathrm{~kg}^{-1} \mathrm{~K}^{-1}$ \\
Surface energy & $\left(\sigma_{\mathrm{SL}}\right)$ & $1.31 \times 10^{-2} \mathrm{~J} \mathrm{~m}^{-2}$ \\
Melting temperature of $\mathrm{Al}$ & $\left(T_{\mathrm{M}}\right)$ & $934 \mathrm{~K}$ \\
Liquidus temperature & $\left(T_{\mathrm{L}}\right)$ & $919 \mathrm{~K}$ \\
Eutectic temperature & $\left(T_{\mathrm{E}}\right)$ & $821 \mathrm{~K}$ \\
Equilibrium partition coefficient & $\left(k_{0}\right)$ & 0.14 \\
\hline
\end{tabular}

Equations (8) and (13) provide expression for calculating the instantaneous temperature of the droplet during recalescence. This is given as

$$
T_{\mathrm{d}}=T_{\mathrm{N}}-\frac{1}{K_{i}}\left(\frac{A_{1} x^{3}}{3}+\frac{A_{2} x^{2}}{2}+A_{3} x+A_{4} t\right)
$$

Equation (13) is solved using a fourth order Runge Kutta scheme to obtain values of ' $x$ ' for time increment ' $\mathrm{d} t$ '. These values of ' $x$ ' are then plugged into (14) to obtain the temperature of droplets, $T_{\mathrm{d}}$. The rate of release of latent heat during solidification of undercooled droplet progressively slows down and becomes equal to the heat dissipation rate by the gas medium. Under this condition recalescence arrest temperature, $T_{\mathrm{R}}$ is obtained by setting $\left(\mathrm{d} T_{\mathrm{d}} / \mathrm{d} t\right)=0$.

After the end of recalescence, further solidification of the remaining melt takes place by mode of segregated solidification. The solid fraction $\left(f_{\mathrm{s}}\right)$ during this stage is calculated using modified Scheil's equation (Flemings 1974)

$$
f_{\mathrm{s}}=1-\left(1-f_{\mathrm{r}}\right)\left\{\frac{T_{\mathrm{M}}-T_{\mathrm{R}}}{T_{\mathrm{M}}-T_{\mathrm{d}}}\right\}^{\frac{1}{\left(1-k_{0}\right)}},
$$

where $f_{\mathrm{r}}$ is fraction solidified during recalescence stage and $T_{\mathrm{R}}$ the recalescence temperature of the droplet. The rate of change of solid fraction during this mode of solidification is obtained by differentiating (15) with respect to $T_{\mathrm{d}}$.

Equations (1) to (15) are solved to obtain the nucleation temperature of droplets, their undercooling, cooling rate prior to nucleation as well as during segregated solidification. The data of thermal and physical properties of Al-4.5 wt\% Cu alloy and $\mathrm{N}_{2}$ gas are given in tables 1 and 2. The results facilitate generation of a complete thermal profile of droplets in melt atomization.

\section{Experimental}

Al-4.5 wt\% $\mathrm{Cu}$ alloy melt was atomized to produce rapidly solidified powders. The details of the atomization process have been described elsewhere (Srivastava et al 2000). Briefly, the process makes use of a straight melt delivery tube of $10 \mathrm{~mm}$ outer diameter concentric to a gas flow channel of convergent-divergent configuration with throat to exit area ratio of $1: 3$. A flow tube of refractory

Table 2. Thermophysical properties of $\mathrm{N}_{2}$ gas (Holman 1989).

\begin{tabular}{lll}
\hline Specific heat & $\left(C_{\mathrm{pg}}\right)$ & $1.04 \times 10^{-3} \mathrm{~J} \mathrm{~kg}^{-1} \mathrm{~K}^{-1}$ \\
Thermal conductivity & $\left(k_{\mathrm{g}}\right)$ & $2.6 \times 10^{-2} \mathrm{~W} \mathrm{~m}^{-2} \mathrm{~K}^{-1}$ \\
Density & $\left(\rho_{\mathrm{g}}\right)$ & $1.16 \mathrm{~kg} \mathrm{~m}^{-3}$ \\
Kinematic viscosity & $\left(\mu_{\mathrm{g}}\right)$ & $1.78 \times 10^{-5} \mathrm{~N} \mathrm{~s} \mathrm{~m}^{-2}$ \\
\hline
\end{tabular}


material is inserted in the melt delivery tube to protect the nozzle from excessive heating. The inner diameter of the flow tube provides diameter of the melt stream during atomization of the melt. Although the process can be used in both upward and downward atomization modes, the latter has been used in the present investigation.

The melting of the alloy was carried out in a resistance heating furnace in a graphite crucible under the cover of argon gas. The atomization of the melt was affected by nitrogen gas. The gas flow was initiated in the nozzle through a high pressure cylinder attached to a gas flow meter. The gas pressure was regulated to $1 \mathrm{MPa}$. Powders were collected through a cyclone separator. These were classified into various size fractions using standard procedure of sieving. The median particle diameter and particle size distribution were determined from the log-normal size distribution plots of the sieve data. The microstructural investigation of powder particles was carried out in a Metallux-3 optical microscope. Secondary dendrite arm spacing of powder particles was measured following quantitative metallographic technique. The cooling rate of powder particles was estimated using the empirical relationship reported by Armstrong and Jones (1979).

\section{Results and discussion}

The size distribution of atomized powders produced at a gas pressure of $1 \mathrm{MPa}$ is shown in figure 3. The particles aggregate is observed to follow a log-normal size distribution with a median particle diameter of $64 \mu \mathrm{m}$ and size range of 30 to $200 \mu \mathrm{m}$. It is worthwhile to mention that the spray enthalpy on the deposition surface in spray forming process is governed by the above size and size distribution of droplets in the spray. As a result, an understanding of the thermal state of droplets and development of their solidification structure is important to control the microstructure of the spray-deposit. The microstructure of

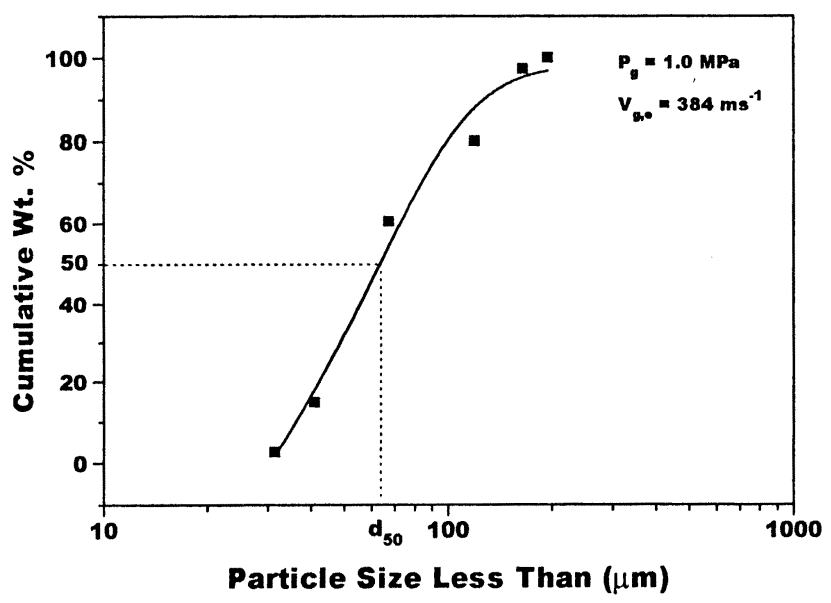

Figure 3. Particle size distribution of gas atomized Al-4.5 wt $\% \mathrm{Cu}$ alloy. two widely different size powder particles is presented in figure 4. Distinct nucleation sites at the surface and centre of atomized powder particles are evident in the above micrographs. These features indicate uncertainty in nucleation event and related undercooling achieved during solidification of atomized droplets. Figure 5 shows the effectiveness of nucleants represented by wetting angle $(\theta)$ and cooling rate of droplets on attainment of undercooling in three widely different size droplets. The cooling rates of droplets used in the above illustration are those obtained prior to their nucleation stage during free flight in the gas stream. The results indicate a strong influence of the catalytic potency of a nucleant on undercooling of the droplets. A droplet containing nucleant having a small wetting angle with the melt would be subjected to heterogeneous nucleation irrespective of its size and cooling rate. However, if a nucleant possesses a poor catalytic potency represented by a large wetting angle, the cooling rate of the droplet becomes important in increasing the undercooling of droplets. This is evident from figure 5 , where we observe a difference in undercooling of $70 \mathrm{~K}$ for $20 \mu \mathrm{m}$ and $250 \mu \mathrm{m}$ size droplets at the same wetting angle $(\theta)$ of 160 degree. Although in atomization
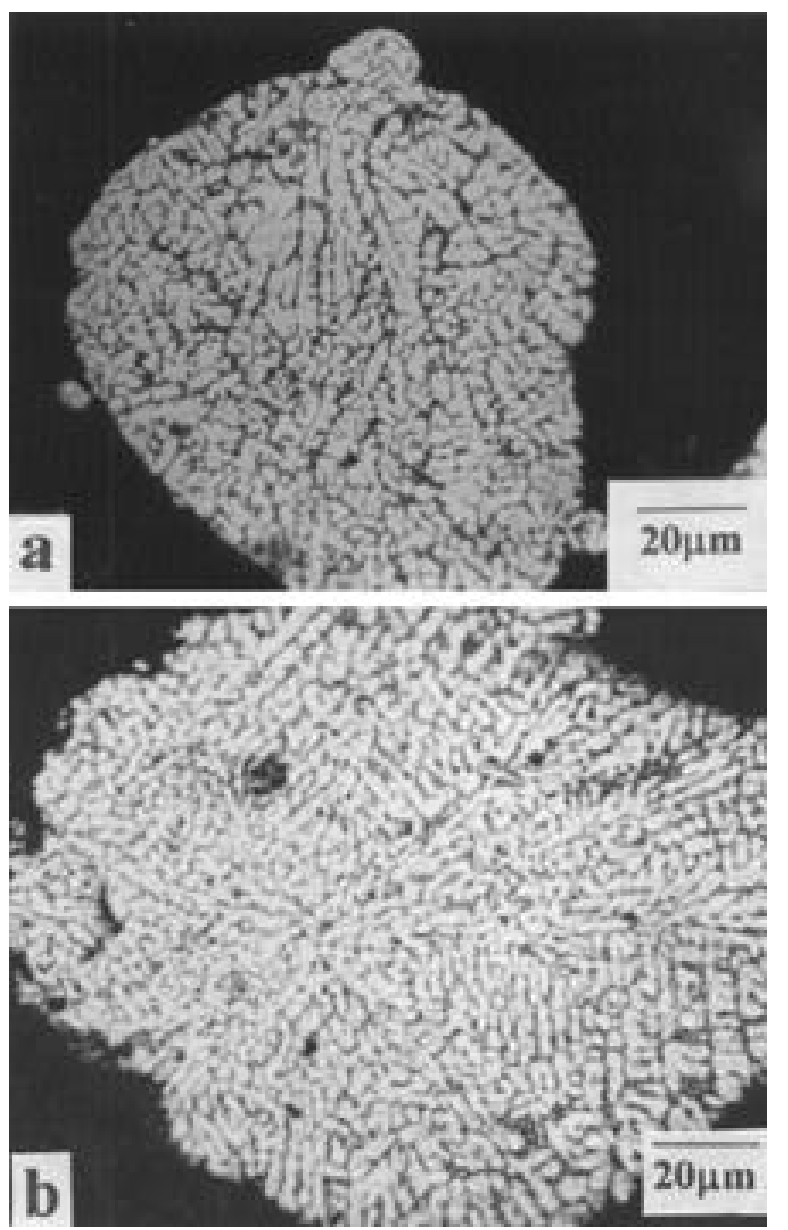

Figure 4. Microstructural features showing distinct nucleation site in (a) surface and (b) centre of powder particles. 
process the catalytic potency of a nucleant does not change but their effect is reduced by isolating them in small volume of the melt.

In subsequent analysis, size dependent nucleation temperatures are used to predict thermal state of droplets. Figure 6 shows variation in undercooling and related cooling rate during nucleation of different size droplets. As the size of the droplet decreases the undercooling of the melt increases. It can be noticed that a droplet of $20 \mu \mathrm{m}$ size undercools by $177 \mathrm{~K}$ compared to an undercooling of only $11 \mathrm{~K}$ for a large droplet of $160 \mu \mathrm{m}$ size. Similar variation is observed in cooling rate of droplets as well. A small droplet of $20 \mu \mathrm{m}$ is subjected to a cooling rate an order of magnitude higher than that of a large droplet of $160 \mu \mathrm{m}$ during time of nucleation. Timetemperature cooling curves showing five distinct solidification regimes of two widely different size droplets of 20 and $120 \mu \mathrm{m}$ size are presented in figures 7 and 8 . It is observed that in a small size droplet, the rise in temperature during recalescence of the undercooled melt is rapid, both the segregated and eutectic solidification regimes are considerably reduced compared to that of the large size

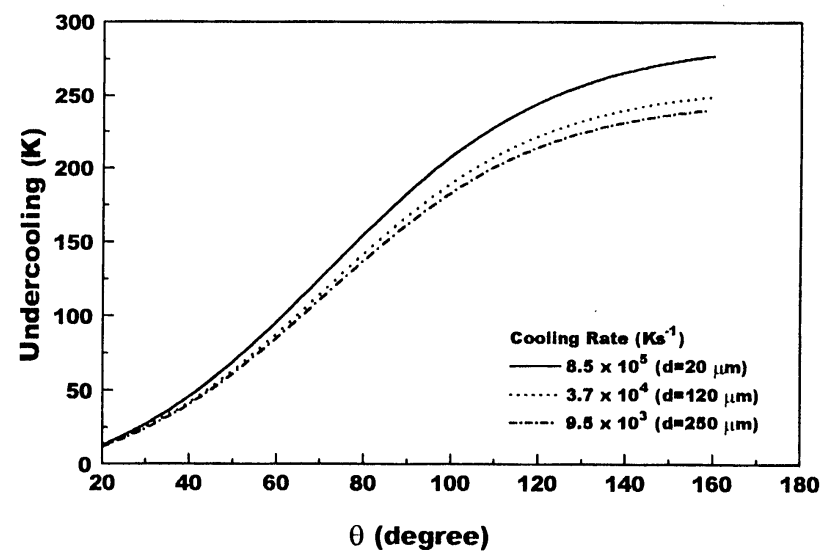

Figure 5. Effect of wetting angle $\theta$ on degree of undercooling of three widely different size droplets.

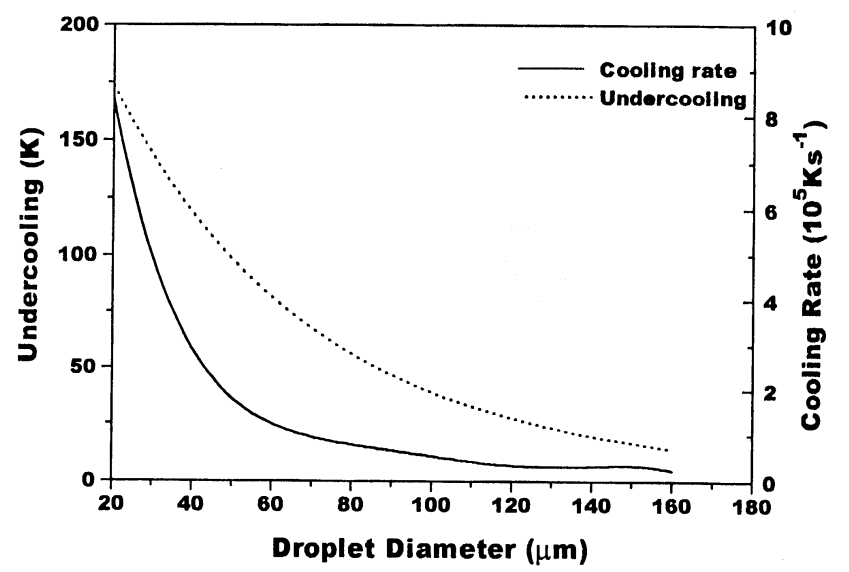

Figure 6. Variation in undercooling and cooling rate during nucleation event of a wide size range of droplets. droplet. However, both the droplets are observed to recalesce to a temperature near the liquidus temperature of the alloy before onset of segregated solidification.

Subsequent to nucleation of the undercooled droplet, the solid-liquid interface temperature rises due to release of the latent heat of fusion. The effect is shown in figure 9 for three different undercoolings of a $20 \mu \mathrm{m}$ size droplet. An undercooling of $175 \mathrm{~K}$ of a $20 \mu \mathrm{m}$ droplet is based on the analysis of size dependent nucleation temperature of the droplet. It is interesting to note that as the normalized distance, a ratio of the interface position of the droplet axis to the diameter of the droplet, increases by 0.4 the interface temperature approaches that of the liquidus temperature of the alloy. However, for a relatively small undercooling of $80 \mathrm{~K}$ this condition is reached at an early stage. In contrast, if the droplet is subjected to a large undercooling of $250 \mathrm{~K}$, the solid-liquid interface advances to a longer distance in undercooled state before reaching to the liquidus temperature. The variation in the interface velocity of the same size droplet is illustrated in figure 10 . A large velocity of the undercooled droplet provides solidification path far from the equilibrium condition

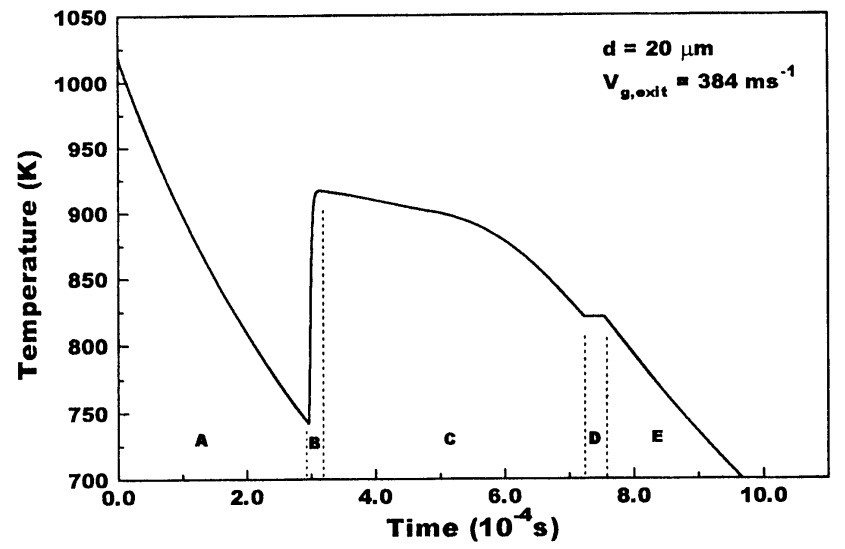

Figure 7. Thermal profile of a $20 \mu \mathrm{m}$ droplet undercooled by $177 \mathrm{~K}$

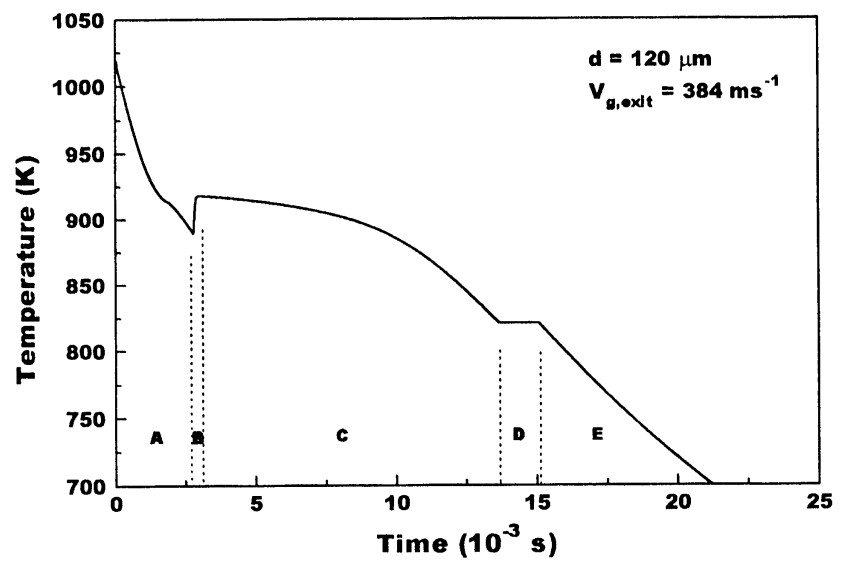

Figure 8. Thermal profile of a $120 \mu \mathrm{m}$ droplet undercooled by $30 \mathrm{~K}$. 


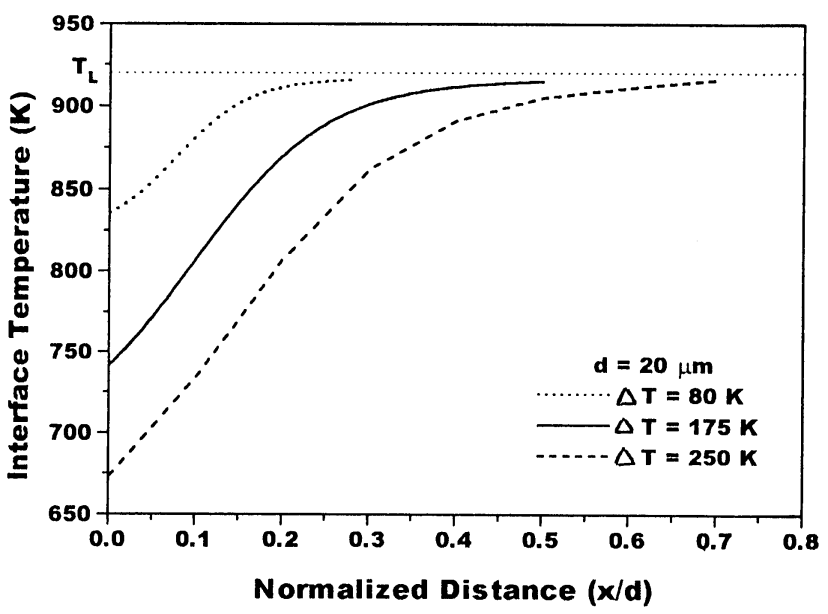

Figure 9. Variation in solid-liquid interface temperature with position of the interface for different undercooling of a $20 \mu \mathrm{m}$ droplet.

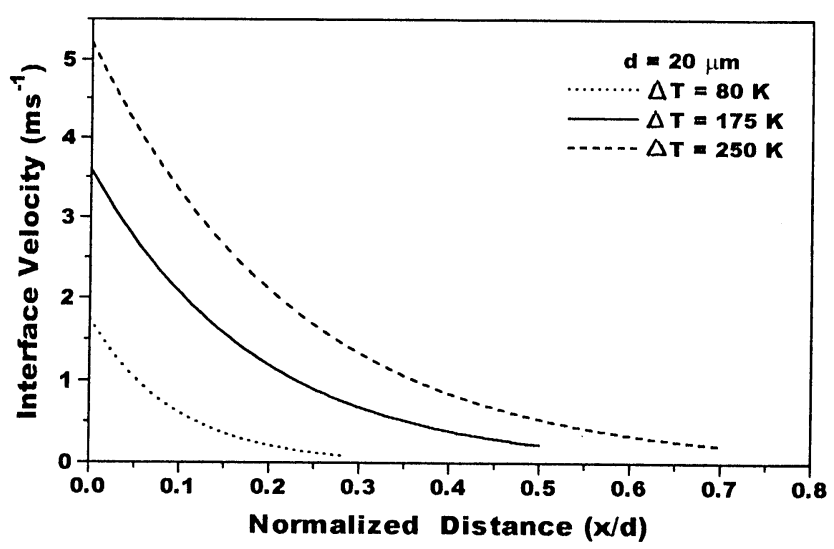

Figure 10. Variation in solid-liquid interface velocity with position of the interface of a $20 \mu \mathrm{m}$ size undercooled droplet.

leading to formation of metastable microstructure in atomized powder particles. The undercooling and recalescence behaviour of a large size range of droplets in gas atomization process are shown in table 3 . It is worthwhile to note that as the droplet size increases with a consequent decrease in its undercooling the initial solid-liquid interface velocity decreases from $3.54 \mathrm{~m} \mathrm{~s}^{-1}$ for a $20 \mu \mathrm{m}$ size droplet to less than $0.5 \mathrm{~m} \mathrm{~s}^{-1}$ for a large size droplet of $160 \mu \mathrm{m}$. Further the fraction of solid formed during recalescence regime is considerably large for a small size droplet. These effects are important to control the microstructural characteristics of droplets during their solidification in the gas atomization processes. A comparison in cooling rate of droplets calculated using heat transfer model and those estimated from secondary arm spacing measurements is presented in figure 11. It is worthwhile to point out that the cooling rates of droplets for this purpose are those calculated during segregated solidification stages. These are an order of magnitude lower than those

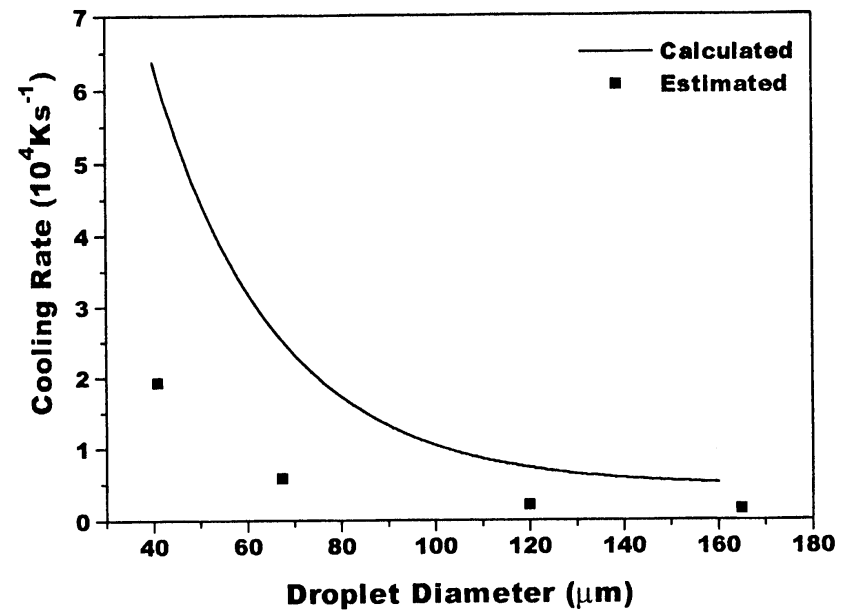

Figure 11. Comparison in cooling rate of droplets estimated from secondary dendrite arm spacing of powder particles and calculated using heat transfer model.

Table 3. Effect of droplet size on undercooling, initial growth velocity and fraction solidified during recalescence.

\begin{tabular}{ccccc}
\hline$d(\mu \mathrm{m})$ & $\Delta T(\mathrm{~K})$ & $T_{\mathrm{R}}(\mathrm{K})$ & $V_{\mathrm{i}}\left(\mathrm{m} \mathrm{s}^{-1}\right)$ & $f_{\mathrm{R}}(\%)$ \\
\hline 20 & 177 & 917 & $3 \cdot 54$ & 53 \\
40 & 112 & 918 & $2 \cdot 24$ & 33 \\
80 & 61 & 918 & $1 \cdot 22$ & 20 \\
160 & 11 & 918 & $0 \cdot 22$ & 5 \\
\hline
\end{tabular}

obtained during cooling of droplets prior to nucleation stage used in figure 6 . This difference arises due to a continuous change in relative velocity between gas and droplets during flight. The heat transfer coefficient at the droplet-gas interface during nucleation event and segregated solidification events are different. Figure 11 shows a good agreement between calculated and estimated cooling rates at least for large size droplets. The deviation in cooling rate from two approaches for small size droplets are basically due to their large undercooling and consequent large fraction of solidification during recalescence stage. The cooling rate does not influence the microstructure evolution during the recalescence regime in small size droplets subjected to large undercooling. In summary, the results of the present investigation highlights the importance of small size droplets in the spray to achieve rapid solidification effects in atomized powder particles as well as those in spray deposition processes.

\section{Conclusions}

(I) The degree of undercooling of droplets in the spray strongly depends on catalytic potency of nucleants in the melt represented by wetting angle $(\theta)$ between melt and nucleant. Volume separation of nucleants in atomization processes gives rise to large undercooling of small size 
droplets. Cooling rate influences degree of undercooling of droplets near homogeneous nucleation condition with a poor catalytic potency of nucleants.

(II) Solidification regimes during recalescence, segregated solidification and eutectic solidification are dependent on size of droplets and their related degree of undercooling. The recalescence temperature of droplets varying from 20 to $160 \mu \mathrm{m}$ size approaches closer to the liquidus temperature of the alloy. This effect, in a highly undercooled droplet, is achieved at a smaller distance of the solid-liquid interface position. The interface velocity during recalescence of the droplet rapidly decreases with a rise in temperature of the interface.

(III) Cooling rates of large size droplets estimated from the measurements of secondary dendrite arm spacing of powder particles are in agreement with those obtained from the model for the regime of segregated solidification. However, deviation in cooling rate of small size droplets predicted by two approaches is due to their large fraction solidified during recalescence stage.

\section{Acknowledgements}

Financial assistance received from the Aeronautics Research and Development Board, Ministry of Defence, New Delhi, for this work is acknowledged.

\section{References}

Adkins N J E and Tsakiropoulous P 1991 Mater. Sci. \& Engg. A133 767

Armstrong G R and Jones H 1979 Solidification and casting of metals (London: Metal Society) p. 34

Boettinger W J and Perepezko J H 1985 Rapidly solidified crystalline alloys (eds) S K Das, B H Kear and C M Adams (Warrendale, Pennsylvania: AMIE) p. 21

Cantor B and Doherty D 1979 Acta Metall. 2733

Drehman A J and Turnbull D 1981 Scr. Metall. 15543

Flemings M C 1974 Solidification processing (NY: McGraw Hill) p. 34

Grant P S, Cantor B and Katgerman L 1993 Acta Metall. Mater. 411097

Herlach D M, Cochrane R F, Egry I, Fetch H J and Greer A L 1993 Int. Mater. Rev. 38237

Hirth J P 1978 Metall. Trans. A9 401

Holman J P 1989 Heat transfer (New Delhi: McGraw Hill Book Co.) p. 644

Klar E and Fesko J W 1984 in Metals handbook (Ohio: ASM) 9th ed. Vol. 7, p. 25

Kurz W and Fisher D J 1989 Fundamental of solidification (Switzerland: Trans Tech Publication)

Lavernia E J, Gutierrez G M, Szekely J and Grant N J 1988 Int. J. Rapid Solidification 489

Lavernia E J and Wu Yue 1996 Spray atomization and deposition (NY: John Wiley \& Sons Ltd.)

Lee EON-SIK and Ahn S 1994 Acta Metall. 423231

Levi C G and Mehrabian R 1982 Metall. Trans. A13 221

Mathur P, Apelian D and Lawley A 1989 Acta Metall. 37429

Ojha S N, Chattopadhyay K and Ramachandrarao P 1985 Mater. Sci. \& Engg. 73177

Ojha S N, Jha J N and Singh S N 1991 Scr. Metall. 25443

Pandey O P, Mishra N S, Ramachandra C, Lele S and Ojha S N 1994 Metall. Mater. Trans. A25 2517

Ranz W and Marshall W 1952 Chem. Engg. Prog. 48141

Sanctis M de 1991 Mater. Sci. \& Engg. 141103

Singh S N, Mishra N S and Ojha S N 1992 Steel Res. 6312

Singh S N and Ojha S N 1992 Int. J. Rapid Solidification 7201

Srivastava V C, Upadhyaya Anish and Ojha S N 2000 Bull. Mater. Sci. 2373

Swaminathan C R 1992 Metall. Trans. B23 651

Unal A 1987 Mater. Sci. \& Technol. 31029 